\title{
Poisoning cases attending emergency department in Dhulikhel Hospital- Kathmandu University Teaching Hospital
}

\author{
Marahatta $\mathbf{S B}^{1}$, Singh $\mathbf{J}^{2}$, Shrestha $\mathbf{R}^{3}$, Koju $\mathbf{R}^{4}$
}

${ }^{1}$ Lecturer, Department of Community Medicine; ${ }^{2}$ Lecturer, Department of Anaesthesia, ${ }^{3}$ Medical Officer, ${ }^{4}$ Assistant Professor, Department of Medicine, Kathmandu University School of Medical Science, Dhulikhel, Nepal

\begin{abstract}
Objective: The objective of the present study is to evaluate the characteristics of acute poisoning cases admitted to emergency department over a one year period. The demographic, clinical and psycho-social aspects of the patients were analysed.

Materials and methods: A hospital based study was carried out in the emergency department, Kathmandu University Teaching Hospital/ Dhulikhel Hospital, Dhulikhel analysing the data of the poisoning cases attended for one year. The study was carried out amongst inpatients attending emergency with acute poisoning.

Results: A total of 54 patients were admitted to the emergency department with acute poisoning. The female-to-male ratio was 1.34:1. Most poisoning occurred in the age group of above 40 years. The mean ages of female and male were $29.87 \pm 14.85$ years and $35.54 \pm 15.02$ years respectively. By occupation $40.38 \%$ of the cases were farmers. Only $35.29 \%$ of the patients were illiterate. $79.24 \%$ of the cases intentionally consume the poison. Organ phosphorus poisoning (OP) was the most common poisoning. Oral route was the commonest route of poisoning accounting 98.1\%. Sixty-six percentage $(66.66 \%)$ of the cases had the poison stored in their home with $27.7 \%$ bought from the market once needed. Among the cases of acute poisoning 5.55\% were fatal.

Conclusion: The following conclusions were reached: (1) females were at greater risk for poisoning than males, (2) self-poisoning cases constituted the majority of all poisonings, and (3) the main agents of self-poisoning were OP poisoning.
\end{abstract}

Key words: poisoning, insecticides, organophosphorus

$\mathrm{P}$ oisoning is a medical emergency and a patient is always invariably rushed to the hospital at the earliest possible moment, irrespective of the amount and nature of poison ingested ${ }^{1}$ All the cases of poisoning are admitted through emergency services where the safety of life of the patient is the main issue for the doctor. Poisoning is one of the major causes of hospitalisation through emergency and is a major public health problem in the $\mathrm{Nepal}^{2}$

The occupational exposure to industrial chemicals and pesticides, accidental or intentional exposure to household and pharmaceutical products and poisoning due to venomous animals, toxic plants and food contamination, all contribute to morbidity and mortality ${ }^{3}$

Present study was taken up to identify the demographic, clinical and psychosocial aspects of the patients which can offer information to initiate preventive measures and to provide a practical guide for the general practitioners and resident hospital staffs towards the management of acute poisoning.

\section{Materials and methods}

A hospital based study was carried out in the emergency department of KUTH/DH Dhulikhel analyzing the data of the poisoning cases attended for over a period of January 2007 till December 2007. A total of 54 cases attended the emergency department during the study period. Data regarding, age, sex, occupation, educational status, types of poisoning, reason for taking the poison were assessed. All the cases which appeared in the emergency during the period were included in the study.

Correspondence

Dr. Sujan B Marahatta

Department of Community Medicine

KUSMS, Dhulikhel, Nepal

E-mail: sujanmarahatta@gmail.com 


\section{Results}

A total of 54 cases attended the emergency department during the study period of one year. The overall femaleto-male ratio was $1.35: 1$. Majority $(73.07 \%)$ of the cases occurred in the joint family. By age group, $29.63 \%$ of the patients were above 40 years, followed by $25.93 \%$ between 21-30 years and 22.23\% in between 31-40 years. The mean ages of female and male were 29.87 \pm 14.85 years and $35.54 \pm 15.02$ years respectively.

As per an occupation, $40.74 \%$ of the respondents constitute farmers, $31.49 \%$ housewives, $16.67 \%$ students and rest of them works in industry and government jobs. Regarding education, $33.34 \%$ of the cases were illiterate, $33.34 \%$ of the cases were literate, $22.23 \%$ had primary education, $7.41 \%$ had secondary level of education and only $3.71 \%$ had higher education.
In this study, $77.78 \%$ of the patients consumed poison intentionally and rest of the cases $22.23 \%$ consumed accidentally. Thirty seven $(37.04 \%)$ of the cases who consumed poison intentionally, did it due to the quarrel in the family, $20.37 \%$ to threaten the family, $11.12 \%$ due to financial crisis, $11.12 \%$ due to love tragedy and rest $24.08 \%$ due to failure in exam, quarrel with neighbour and insecurity of job. Amongst the type of poison, organophosphorus poisoning constitute the commonest cause $74.07 \%$, followed by antidepressant drug $16.66 \%$, Zinc phosphide 5.55\%, Benzodiazepines $1.85 \%$ and alcohol $1.85 \%$ respectively. $66.66 \%$ of the patients obtained the poison being stored at home however, $27.77 \%$ bought from the market, 3.7\% obtained from friend and rest $1.85 \%$ bought from pharmacy. Oral route (98.11\%) constitute major route of intake of poison.

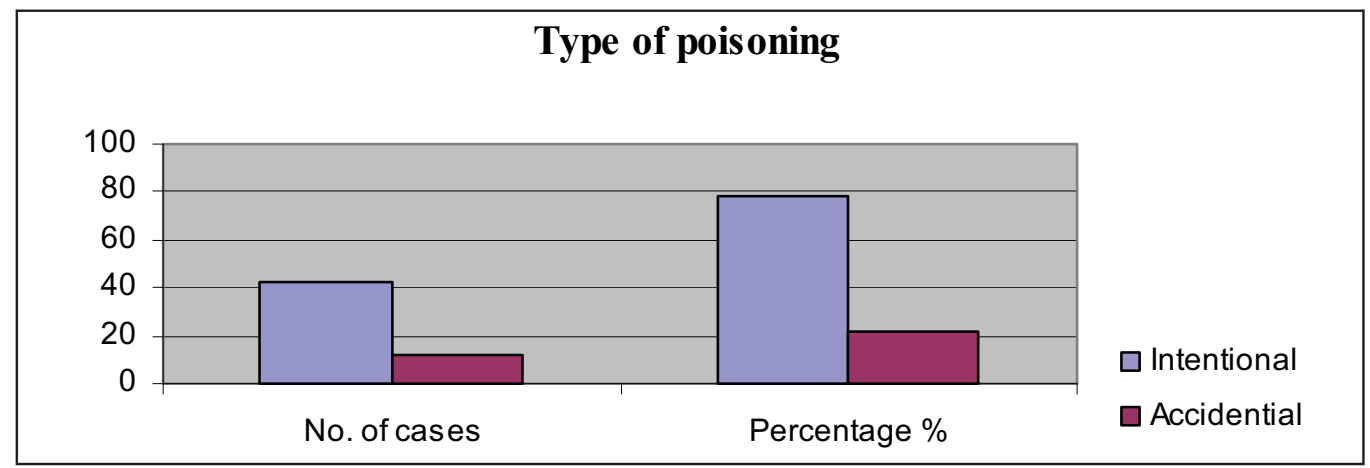

Fig 1: Type of Poisoning

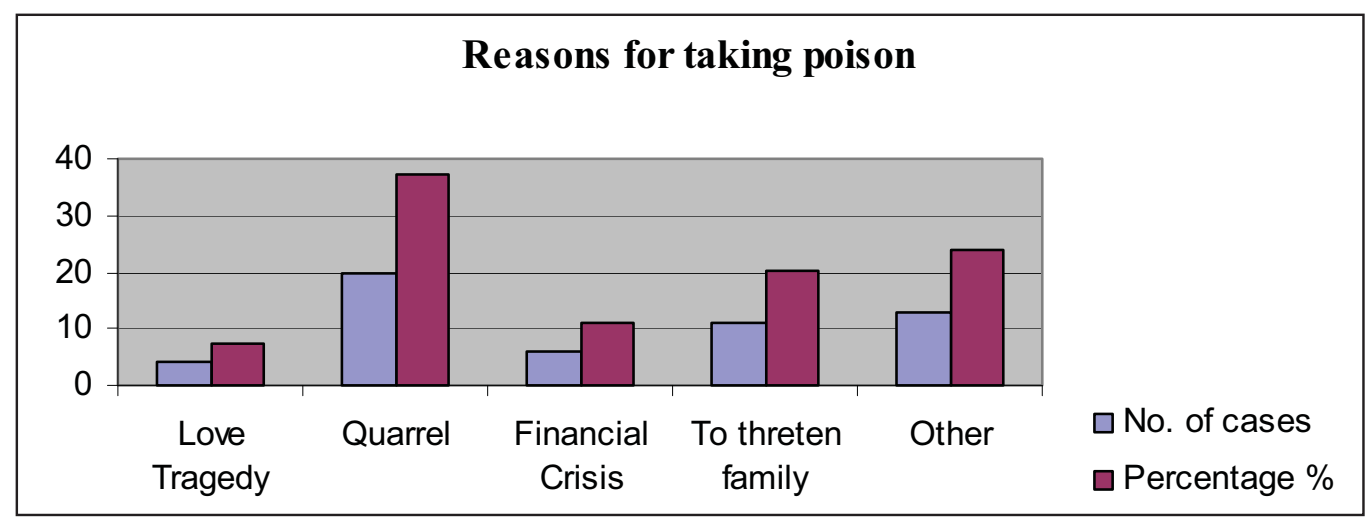

Fig 2: Reason of taking poison

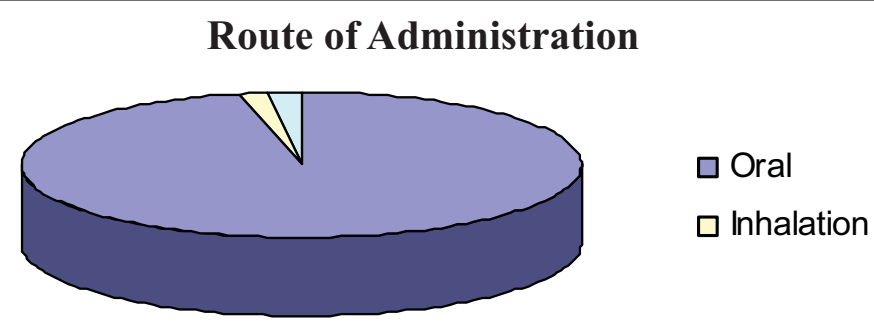

Fig 3: Route of Administration 
Table 1: Occupation of the patients

\begin{tabular}{|l|c|c|}
\hline Occupation & No. of cases & Percentage \% \\
\hline Farmer & 22 & 40.74 \\
\hline Service holder & 1 & 1.86 \\
\hline Students & 9 & 16.67 \\
\hline Housewife & 17 & 31.49 \\
\hline Laborer & 1 & 1.86 \\
\hline Industry & 2 & 3.71 \\
\hline Business-service & 1 & 1.86 \\
\hline Other & 1 & 1.86 \\
\hline Total & $\mathbf{5 4}$ & $\mathbf{1 0 0}$ \\
\hline
\end{tabular}

Table 2: Level of Education

\begin{tabular}{|l|c|c|}
\hline Educational Status & No. of cases & Percentage \% \\
\hline Illiterate & 18 & 33.34 \\
\hline Literate & 18 & 33.34 \\
\hline Primary Education & 12 & 22.23 \\
\hline Secondary- SLC & 4 & 7.41 \\
\hline Higher Education & 2 & 3.71 \\
\hline Total & $\mathbf{5 4}$ & $\mathbf{1 0 0}$ \\
\hline
\end{tabular}

Table 3: Family Type

\begin{tabular}{|l|c|c|}
\hline Family Type & No. of cases & Percentage \% \\
\hline Joint $>5$ & 38 & 70.37 \\
\hline Nuclear $<5$ & 16 & 29.63 \\
\hline Total & $\mathbf{5 4}$ & $\mathbf{1 0 0}$ \\
\hline
\end{tabular}

Table 4: Types of Poison

\begin{tabular}{|l|c|c|}
\hline & No. of cases & Percentage \% \\
\hline OP & 40 & 74.07 \\
\hline Zn- P & 3 & 5.55 \\
\hline Alcohol & 1 & 1.85 \\
\hline Benzodiazepines & 1 & 1.85 \\
\hline Antidepressant & 9 & 16.66 \\
\hline Total & $\mathbf{5 4}$ & $\mathbf{1 0 0}$ \\
\hline
\end{tabular}

Table 5: Place of Obtaining Poison

\begin{tabular}{|l|c|c|}
\hline Place & No. of cases & Percentage \% \\
\hline Store in home & 36 & 66.66 \\
\hline Market & 15 & 27.77 \\
\hline Pharmacy & 1 & 1.85 \\
\hline Neighbor-friends & 2 & 3.7 \\
\hline Total & $\mathbf{5 4}$ & $\mathbf{1 0 0}$ \\
\hline
\end{tabular}




\section{Discussion}

Acute poisoning is an important clinical emergency and contributor to morbidity and mortality. Early diagnosis, treatment and prevention are crucial in reducing the burden of poisoning-related injury in any country. Baseline epidemiological data depicting the susceptible groups in the community, high-risk circumstances, psychosocial aspects of poisoning, evolve strategies for strengthening poisoning prevention and management at all health care levels.

The present study revealed that the poisoning was more common in female compared to male (1.35:1). Similar finding was obtained in the study done in Bir hospital with female male ratio of $1.3: 1^{2}$. However a study done in Kathmandu Medical College revealed female male ratio of 1.09: $1^{4}$ The finding of the retrospective study to evaluate the characteristics of cases of acute poisoning revealed the $\mathrm{F} / \mathrm{M}$ ratio of $2: 1^{5}$ A study done in university hospital emergency department in Turkey revealed F/M ratio of $3.5: 1^{6}$. Female preponderance in this study could be accounted to the fact that females are often exposed to the stress and strain of day to day life in our society. By age group $29.63 \%$ of the patients were above 40 years with $25.93 \%$ amongst the age group of 21 to 30 years, implicating that patients above 20 years of age group constitute the major risk group. The study done in KMC revealed that most of the cases $(38.8 \%)$ were in between $21-30$ years ${ }^{4}$.

In our study, $40.74 \%$ of the respondents constitute farmers, $31.49 \%$ housewives, $16.67 \%$ were students. In contrary, students were found to be commonly involved in poisoning $(35.8 \%)$ however second place occupied by the housewives $(22.3 \%)^{4}$, similar results with our study. Poisoning is more prevalent among farmers. These groups are more vulnerable for poisoning which may be due to fact that they are under continuous financial and other stress during the life. In respect of the incidence of literacy status in the present study, $35.29 \%$ of the cases were illiterate, $29.4 \%$ of the cases were literate and rests of them have formal education. Similar study done in India showed $83.9 \%$ of the victims were literate at the time of incidence. It is seen that majority of cases were literates and $(16.1 \%)$ are illiterate ${ }^{1 .}$ Failure in life and tolerance to the problem are better understood by literates than illiterates which might be the reason of more literates presenting than illiterates. The fact behind the trend can be explained as the literate mass mostly subjected to great stress and strain, which make them vulnerable to attempt self poisoning.

In this study, $77.78 \%$ of the patients consumed poison intentionally and rest of the cases $22.23 \%$ consumed accidentally. However the study done in Bir Hospital reveals that ninety-seven cases $(98.0 \%)$ were intentional poisoning for suicidal attempt and two cases (2.0\%) had accidental poisoning ${ }^{2}$. Similar study done in Turkey revealed that deliberate self-poisoning was most common cause of poisoning (58.6\%), and followed by accidental exposure $(39.1 \%)^{6}$.

As per our findings, $37.04 \%$ of the cases, who consumed poison intentionally, did it due to the quarrel in the family, $20.37 \%$ to threaten the family, $11.12 \%$ due to financial crisis, $11.12 \%$ due to love tragedy and rest $24.08 \%$ due to failure in exam, quarrel with neighbor and insecurity of job. Misunderstandings at the family level have been the prime factor responsible for intentional poisoning.

The present study revealed that amongst the type of poison, organophosphorous poisoning constitute the commonest cause $74.07 \%$, followed by antidepressant drug $16.66 \%$, Zinc phosphide $5.55 \%$, benzodiazepines $1.85 \%$ and alcohol $1.85 \%$ respectively. The nearby area of Dhulikhel being mainly agricultural area, insecticides are available abundantly and easily in local shops. The easy availability and cheaper prices have made them popular killer agent especially among the farmers in the present study.

The common insecticides used for poisoning were organophosphorus compounds mainly Methyl Parathion (Metacid) and Dichlorovos (Nuvan). This is consistent with other studies carried out in $\mathrm{Nepal}^{8-15}$.There were $21(21.2 \%)$ cases of Metacid poisoning and $16(16.2 \%)$ cases of Nuvan poisoning. In a small study from eastern town of Dharan, $62 \%$ poisoning patients had Metacid poisoning ${ }^{2}$.However, a study done in Turkey revealed that the main agents of self-poisoning were medicinal drugs, with antidepressants used most frequently. It was also found that unintentional poisoning commonly resulted from intake of foods, especially mushrooms ${ }^{5}$

Among all the cases $66.66 \%$ of the cases had stored poison at home, $27.77 \%$ bought from the market, $3.7 \%$ obtained from friend and rest $1.85 \%$ bought from pharmacy. The easy availability of the poisonous insecticides in the market for the sake of agricultural purpose has been responsible to gain easy assess to such poison. Oral route $98.11 \%$ constitute major route of intake of poison. Only $1.88 \%$ poisoning was due to inhalation. None of the patient has been found to use $\mathrm{I} / \mathrm{M}$ or $\mathrm{I} / \mathrm{V}$. The similar finding was reported on the study done in $\mathrm{KMC}$ where $86.5 \%$ constitute oral intake followed by $13.5 \%$ poisoning due to inhalation. ${ }^{3}$ Among the cases of acute poisoning $5.55 \%$ were fatal.

\section{Conclusion}

In our study almost all poisoning were intentional to harm oneself. With the increasing stress in life, suicide among adolescents and young adults is a common public 
health problem. Patients with intentional poisoning must undergo psychiatric consultation during their stay in the hospital for the treatment poisoning. This will minimize the risk of next attempt of self harm. Farmers have been found to be the major risk group by occupation. Hence, strict rules must be followed regarding sale of pesticides. The pesticides must be sold in the presence of a witness who should be known to the client.

\section{References}

1. Dash SK, Raju AS, Mohanty MK, Patnaika KK, Siddharatha P, Mohanty S. Socioeconomic Profiles of Poisoning Cases. JIAFM. 2005; 27 : 133-8.

2. Singh DP, Acharya RP. Patterns of poisoning in Nepal. J Inst Med. 2006; 28:3-6.

3. Lal SB, Al-Wahaibi SS, Al-Riyam MM, AlKharusi K. Profile of acute poisoning cases presenting to health centres and hospitals in Oman Eastern. Mediterranean Health Journal. 2003; 9: 944-54.

4. Khadka SB, Ale SB. A study of poisoning cases in emergency Kathmandu Medical College Teaching Hospital. KUMJ. 2005; 3: 388-91.

5. Baydin A, Yardan T, Aygun D, Doganaya Z, Nargis C, Incelatin O. Retrospective evaluation of emergency service patients with poisoning: A 3-year study. Advances in therapy. 2005; 22: 650-8.
6. Gulohglu C, Kara IH. Acute poisoning cases admitted to a university hospital emergency department in Diyarbakir, Turkey. Human \& experimental toxicology. 2005; 24: 49-54.

7. Rani MA. Retrospective analysis of profile of acute poisoning cases in a tertiary care hospital in eastern Nepal: a four year data base from 19941997. J Nep Med Assoc. 1999; 38: 23-8.

8. Kafle KK, Nepal MK, Sharma SR, Pokharel RP. Poisoning cases at T.U. Teaching Hospital. J Inst Med. 1989; 11: 297-301.

9. Suvedi BK. A retrospective study of poisoning cases at Bir Hospital, Nepal. J Inst Med. 1990; 12: 296-302.

10. Kafle KK, Gyawali KK. Organ phosphorous commonest poisoning agent. J Inst Med. 1992; 14: 228-33.

11. Poudyal BP. Poisoning: Pattern and Profile of Admitted Cases in a Hospital in Central Nepal. J Nep Med Assoc. 2005; 44: 92-6.

12. Ghimire RH, Sharma SP, Pandey KR. A Comparative Study of Acute Poisoning in Nepal at Tertiary and Secondary Level Hospitals. J Nep Med Assoc. 2004; 43: 130-3.

13. Gupta SK, Joshi MP. Pesticide Poisoning Cases Attending Five Major Hospitals of Nepal. J Nep Med Assoc. 2002; 41: 447-56.

14. Prasad PN, Karki P. Poisoning cases at TUTH emergency: a one-year review. J Inst Med. 1997; 19: 18-24. 